\title{
Research Paper: The Effect of Laser Therapy and Ischemic Compression on Active Trigger Points in Upper Trapezius Muscle
}

Saeed Rezaei ${ }^{1}$ Q, Azadeh Shadmehr ${ }^{* *}$ Q, Siamak Bashardoust Tajali ${ }^{1}$, Behrooz Attarbashi Moghadam ${ }^{1}$, Shohreh Jalaei $^{1}$

1. Department of Physiotherapy, School of Rehabilitation, Tehran University of Medical Sciences, Tehran, Iran.

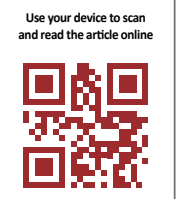

ditation: Rezaei S, Shadmehr A, Bashardoust Tajali S, Attarbashi Moghadam B, Jalaei Sh. The Effect of Laser Therapy and Ischemic Compression on Active Trigger Points in Upper Trapezius Muscle. Journal of Modern Rehabilitation. 2019; 13(4):221226. http://dx.doi.org/10.32598/JMR.13.4.221

http://dx.doi.org/10.32598/JMR.13.4.221

Article info:

Received: 21 Apr 2019

Accepted: 20 Aug 2019

Available Online: 01 Oct 2019

Keywords:

Myofascial pain syndromes, Pain, Trigger points, Laser therapy, Manual therapy

\section{A B STRACT}

Introduction: Myofascial Pain Syndrome (MPS) is a common muscular disorder characterized by a referral pain to a particular area after irritating the myofascial trigger point. This study aimed to determine the combined treatment effect of laser therapy and ischemic compression of an active myofascial trigger point in the upper trapezius muscle

Materials and Methods: This is a clinical trial study conducted on 15 subjects with Active Trigger Points (ATPs). In one session, 15 subjects received laser therapy and ischemic compression. The assessment was done immediately after the treatment. We used the visual analog scale for the measurement of pain intensity, algometry (FG-5020, Taiwan made) for pressure pain threshold, and goniometer for cervical lateral flexion.

Results: The cervical lateral flexion after the intervention was significantly higher than that before the intervention $(\mathrm{P}<0.001)$. Also, the post-operative pressure pain threshold was significantly higher than that before the intervention $(\mathrm{P}<0.001)$. The level of pain decreased after the intervention, but this difference was not statistically significant $(\mathrm{P}=0.90)$.

Conclusion: according to this study, the laser therapy combined with ischemic compression can significantly change the pressure pain threshold and cervical lateral flexion in patients with active trigger points in their upper trapezius muscles. 


\section{Introduction}

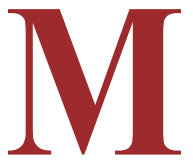

yofascial Pain Syndrome (MPS) is a common muscular disorder characterized by a referral pain to a particular area after irritating the myofascial trigger point. The myofascial trigger point is a hyperirritable spot in the skeletal muscle associated with a palpable nodule in a taut bund. MPS is one of the most prevalent causes of chronic musculoskeletal pain. Headaches, shoulder pain, and chronic low back pain are the leading causes of time work waste. Most chronic MPS related pains will relieve with the correct diagnosis and proper treatment. Trigger points occur more in postural muscles, which maintain the body posture [1]

The Upper Trapezius Muscle (UTM) is one of the most involved muscles, which is frequently stricken with trigger points [2]. Generally, UTM related trigger points are associated with referral pain to the posterior lateral side of the neck and back of the ear to the site of the temporal area [3]. There are two kinds of trigger points: the Active Trigger Points (ATPs) and the Latent Trigger Points (LTPs). ATPs cause spontaneous pain; i.e. these points will hurt without applying any physical contact. LTPs have all characteristics of ATPs like taut bund, local twitch, and referral pain after compression, but these points don't cause spontaneous symptoms [2, 4-6]. Several therapeutic approaches are available like ischemic compression, massage, dry needling, spray and stretch, electrical stimulation, ultrasound, and laser therapy [7].

Many studies have been conducted on the therapeutic effects of laser therapy. Low-power laser therapy improves local microcirculation that helps improve oxygenation $[8,9]$. Clinical results of using low-power laser therapy in musculoskeletal pain and MPS treatment are contradictory [10]. Another technique is ischemic compression, and numerous studies have investigated its effectiveness. Travell and Simon emphasized that manual compression on the contracted nodule would reduce the height and thus increase the length of the sarcomeres in the involved muscles [11]. There is a study comparing Laser therapy and Ischemic compression ,but due to the lack of combined effects evaluation and functional variable; It is not possible to discuss about the the exact effects of these two method [12]. Regarding the prevalence of trigger points in different muscles and their effects on the performance and life of the patients, choosing the proper treatment method and saving time is very important. This research was designed to investigate the synergistic effects of using combined ischemic compression and low-power laser therapy.

\section{Methods}

This research is a clinical trial study conducted on 15 individuals with ATPs. The study population included people who attended the rehabilitation clinic of the Tehran University of Medical Science. The inclusion criteria included patients who aged 20 to 40 years, were diagnosed with one ATP in UTM, suffered from a painful neck for less than one year with the pain intensity of at least 3 based on the Visual Analog Scale (VAS) (which is considered as a moderate pain) [13-15]. The exclusion criteria included comorbid with a cardiovascular or neurological condition, infection, inflammatory disease, radicular pain, or too many ATPs. Trigger points were diagnosed manually. The trigger points are confirmed by Simons' model as follows:

The patient complained of pain with a specific distribution from the trigger point, palpable taut bund in muscles, and specific tenderness of trigger point at a point along the taut bund [16]. Each patient was examined by the therapist and received the laser and ischemic compression. Treatment was done for one session. Outcomes were evaluated by pressure pain threshold, pain intensity, and active cervical lateral flexion. The combinatory effect of ischemic compression and laser therapy on these three variables was analyzed with VAS, algometry (FG-5020, Taiwan made), and goniometer to measure pain intensity, pressure pain threshold, and cervical lateral flexion, respectively.

The algometry method has acceptable validity and reliability [17]. The algometer was put on the trigger points, and the pressure was slowly increased. When the pressure became painful, and the examiner would record the pressure value $(\mathrm{N})$. This test was repeated three times, and the mean value was recorded as the pressure pain threshold score.

To measure pain intensity based on VAS, the participants were provided with a ruler of $10-\mathrm{cm}$ length. And it was explained to them that 0 means no pain and 10 means maximum pain. The patient could mark any point in the ruler. The patients mark one point according to their pain, and then the length of the mark was recorded by the therapist in millimeters.

For the measurement of cervical lateral flexion, first, the patients were asked to sit straight, then the action was taught to him. So that their ear could come close to the opposite shoulder as far as possible and without any extra moves in the neck or shoulders. Afterward, the patients returned to the initial position. The goniometer 
axis was put on the spinous process of the seventh cervical vertebrae, and the straight arm was perpendicular to the ground. Then, the moving arm placed over the external occipital protuberance of the occipital bone. The patient was then asked to perform the movement according to the training, and the therapist read the moving arm's degree [18]. Measurements were performed three times, and the mean values were recorded as lateral cervical flexion.

Before initiating the treatment, the trigger point was determined. The participants were treated with lowpower laser therapy and ischemic compression. The laser device was an infrared $808-\mathrm{nm}$ continuous wave $860 \mathrm{x}$ with the peak power of $500 \mathrm{~mW}$ (made by NOVIN). The patient should sit flat on the chair. In the next step, a low-power laser therapy device was set with a dose of $6 \mathrm{~J} / \mathrm{cm} 2$. Then, the ischemic compression was applied; the therapist applied pressure until the subject reported moderate but tolerable pain. When the individual declared that their pain decreased, the therapist increased the load so that the pain reaches its previous value. This pressure was maintained for 60 seconds [19]. Randomly, some patients underwent laser therapy followed by ischemic compression, some others vice versa. All data were collected before the treatment session and immediately after the intervention.

\section{Statistical analysis}

The Kolmogorov-Smirnov test was used to evaluate numerical variables in terms of their distribution. The paired t test was used to compare VAS, PPT, and cervical lateral flexion results of the intervention before and after the intervention. The variable for the cervical lateral flexion was normally distributed, but two other variables were not. The variable for the pain intensity was normalized using Johnson transformation, but the pressure pain threshold did not change in any statistical test. Therefore nonparametric test was used for pressure pain threshold and parametric tests were used for lateral cervical flexion and pain intensity. All statistical analyses were performed in SPSS version 18, with a significant level of 0.05 .

\section{Results}

In this study, 15 patients with an active trigger point were treated with laser therapy and the ischemic compression technique. The power of the study was 0.8 . The Mean \pm SD of patients' age and duration of disease were $26.53 \pm 3.90$ and $6.13 \pm 3.62$ years, respectively (Table 1 ). The numerical indexes of the cervical lateral flexion of the neck, pain intensity VAS, and Pressure Pain Threshold (PPT), before and after the treatment are presented and compared in Table 2. As it can be seen, the cervical lateral flexion after the intervention $(34.13 \pm 2.09$ degrees) was significantly higher than that before the intervention ( $32.02 \pm 2.37$ degrees) $(\mathrm{P}<0.001)$, additionally, the postoperative myofascial pressure pain threshold $(15.50 \pm 2.86 \mathrm{~N})$ was significantly higher than before the intervention $(12.00 \pm 2.15 \mathrm{~N})(\mathrm{P}<0.001)$.

Table 1. Numerical indexes of age and duration of disease of participants

\begin{tabular}{ccc}
\hline Variables & Mean \pm SD & Range \\
\hline Age, $y$ & $26.53 \pm 3.90$ & $32-20$ \\
\hline Duration of disease, $y$ & $6.13 \pm 3.62$ & $12-2$ \\
\hline
\end{tabular}

$J \mathrm{MR}$

Table 2. The comparison between cervical lateral flexion (degree), pain intensity (VAS) and pressure pain threshold (N) before and after treatment

\begin{tabular}{|c|c|c|c|c|c|}
\hline \multirow{2}{*}{ Variables } & \multicolumn{2}{|c|}{ Before treatment } & \multicolumn{2}{|c|}{ After treatment } & \multirow{2}{*}{$\mathbf{P}$} \\
\hline & Mean $\pm S D$ & Range & Mean $\pm S D$ & Range & \\
\hline Lateral flexion, degree & $32.06 \pm 2.37$ & $38-29$ & $34.13 \pm 2.09$ & $38-31$ & $>0.001 *$ \\
\hline Pain intensity & $45.26 \pm 25.59$ & $75-5$ & $40.73 \pm 11.29$ & $58-6$ & $0.90^{*}$ \\
\hline Pressure pain threshold, $\mathrm{N}$ & $12.00 \pm 2.15$ & $15-10$ & $15.50 \pm 2.86$ & $20-10$ & $0.001 * *$ \\
\hline
\end{tabular}




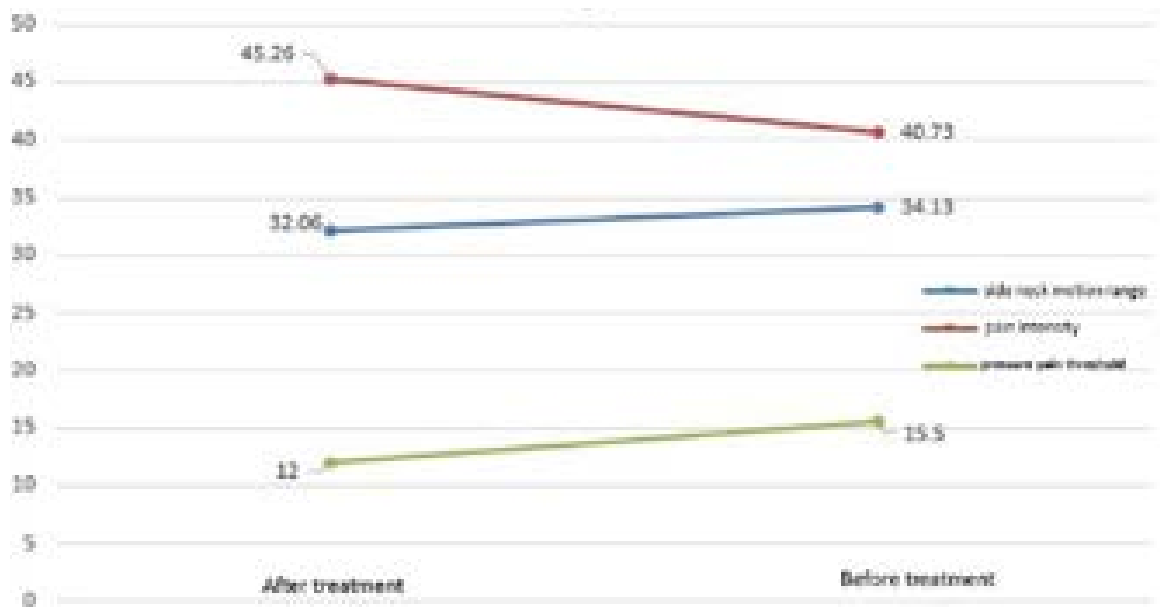

Figure 1. Mean values of cervical lateral flexion (degree), pain intensity (VAS) and pressure pain threshold (N) before and after the treatment

The level of pain decreased after the intervention, but this difference was not statistically significant $(\mathrm{P}=0.90)$. Figure 1 presents the mean for cervical lateral flexion of the neck, pain level VAS, and the PPT before and after the treatment. As can be seen, the level of pain decreased after the intervention, and cervical lateral flexion and the pressure pain threshold increased.

\section{Discussion}

This study aimed to investigate the synergistic effects of low-power laser therapy and ischemic compression on the treatment of active trigger points in the upper trapezius muscle. Several studies, such as the Hakguder study [20], on the effectiveness of laser therapies on trigger points, and the study of Aguilera [21] on the effectiveness of these two treatments, have been carried out. About the low-power laser therapy in the treatment of trigger points, many studies reported dual responses. Considering the combined use of most clinical trials, no study has been conducted on the synergistic effects of these two therapies.

A wealth of evidence supports the benefits of laser therapy. Nowadays, the knowledge of using laser therapy is rapidly increasing as well as its mechanism of response and the optimal dosage for tissue [22].

In some studies, such as Dr. Thorsen, no difference was found between the group of laser-therapy and placebotherapy on pain variables [23].

The effect of laser therapy on its biostimulation effects is reflected in the electromagnetic effects of laser energy on the tissues of the body, which stimulates all types of cellular functions. In the case of disorders, the energy level of the cell changes. Laser therapy affects these conditions. The hypothesis that laser therapy has analgesic, myorelaxant, tissue healing, and biostimulation effects is supported by numerous placebo-controlled clinical studies $[8,24]$. Dual clinical results in the use of laser therapy in musculoskeletal pain are probably due to the inadequate use of energy in many cases, which has been the cause of the ineffectiveness of a low-power laser therapy

One of the manual techniques used to treat trigger points is ischemic compression. Based on the evidence, the taut band of trigger points and nodules is due to a shortage of sarcomeres in muscle fibers that produce contraction nodules and disks [1]. Presumably, the manual pressure applied to these contraction knobs reduces the height and thus increases the length of the sarcomeres in the involved muscle [25].

\section{Conclousion}

This study aimed to find the effectiveness of ischemic compression combined with laser therapy on upper trapezius muscle to reduce pain and pain threshold and improve the range of motion.

The statistical results of this study indicate the significant effects of low-power laser therapy and ischemic compression on reducing clinical parameters except for pain sensation. This event can be attributed to the ischemic compression technique. Ischemic compression is one of the common manual therapy techniques, but this treatment is somewhat painful. One of the problems is the pain created by this technique [26]. 
It has been suggested that laser therapy can break the defective cycle at the trigger points by reducing spasm in the capillaries that are essential for oxygenation of the muscles and increasing the production of ATP and its effects on the surface of the endorphins [24]. The combination of these two therapies had a decisive impact on the cervical lateral flexion and the pain threshold. The results of Kanan study are consistent with the present study. He studied the effect of therapeutic ultrasound, laser, and ischemic compression in reducing pain and improving the cervical range of motion in patients with myofascial trigger points [12]. Considering the importance of medical costs, reducing expenses, and saving time in the treatment of myofascial pain syndrome is very important.

The limitations of the study comprised a low sample size, no long-term follow up of the patients, and the absence of the control group. It is suggested that these two interventions be compared separately with each other. Future studies could compare the effectiveness of ischemic compression and laser therapy with other advanced techniques.

\section{Ethical Considerations}

\section{Compliance with ethical guidelines}

Compliance with ethical guidelines: The research project was ethically approved by Tehran University of Medical Sciences (Code: IR.TUMS.VCR.REC.1397.348 )

\section{Funding}

The research was supported by the Tehran University of Medical Sciences (TUMS) and Health Services (Grant no.: 98-01-32-40003).

\section{Authors contributions}

Data gathering, writing- original drafts: Azadeh Shadmehr, Saeed Rezaei; Review and editing, visualization, supervision: All author.

\section{Conflict of interest}

The authors declared no conflict of interest

Acknowledgements

We would thank the personnel of the School of Rehabilitation

\section{References}

[1] Simons DG, Travell JG, Simons LS. Travell \& Simons' myofascial pain and dysfunction: Upper half of body. Philadelphia: Lippincott Williams \& Wilkins; 1999. https://books. google.com/books?id=sU0XupX7DGsC\&dq

[2] Sarrafzadeh J, Ahmadi A, Yassin M. The effects of pressure release, phonophoresis of hydrocortisone, and ultrasound on upper trapezius latent myofascial trigger point. Archives of Physical Medicine and Rehabilitation. 2012; 93(1):72-7. [DOI:10.1016/j.apmr.2011.08.001] [PMID]

[3] Okhovatian F, Mehdikhani R, Naimi SS. RETRACTED: Comparison between the immediate effect of manual pressure release and strain/counterstrain techniques on latent trigger point of upper trapezius muscle. Clinical Chiropractic. 2012; 15(2):55-61. [DOI:10.1016/j.clch.2012.04.003]

[4] Celik D, Mutlu EK. Clinical implication of latent myofascial trigger point. Current Pain and Headache Reports. 2013; 17(8):353. [DOI:10.1007/s11916-013-0353-8] [PMID]

[5] Llamas-Ramos R, Pecos-Martín D, Gallego-Izquierdo T, Llamas-Ramos I, Plaza-Manzano G, Ortega-Santiago R, et al. Comparison of the short-term outcomes between trigger point dry needling and trigger point manual therapy for the management of chronic mechanical neck pain: A randomized clinical trial. Journal of Orthopaedic \& Sports Physical Therapy. 2014; 44(11):852-61. [DOI:10.2519/jospt.2014.5229] [PMID]

[6] Bron C, Dommerholt JD. Etiology of myofascial trigger points. Current Pain and headache Reports. 2012; 16(5):43944. [DOI:10.1007/s11916-012-0289-4] [PMID] [PMCID]

[7] Gulick DT, Palombaro K, Lattanzi JB. Effect of ischemic pressure using a Backnobber II device on discomfort associated with myofascial trigger points. Journal of Bodywork and Movement Therapies. 2011; 15(3):319-25. [DOI:10.1016/j. jbmt.2010.06.007] [PMID]

[8] Pal US, Kumar L, Mehta G, Singh N, Singh G, Singh M, et al Trends in management of myofacial pain. National Journal of Maxillofacial Surgery. 2014; 5(2):109-16. [DOI:10.4103/09755950.154810] [PMID] [PMCID]

[9] Deana NF, Zaror C, Sandoval P, Alves N. Effectiveness of low-level laser therapy in reducing orthodontic pain: A systematic review and meta-analysis. Pain Research and Management. 2017; 2017:8560652. [DOI:10.1155/2017/8560652] [PMID] [PMCID]

[10] Beckerman H, de Bie RA, Bouter LM, De Cuyper HJ, Oostendorp RAB. The efficacy of laser therapy for musculoskeletal and skin disorders: A criteria-based meta-analysis of randomized clinical trials. Physical Therapy. 1992; 72(7):483-91. [DOI:10.1093/ptj/72.7.483] [PMID]

[11] Simons DG. Understanding effective treatments of myofascial trigger points. Journal of Bodywork and Movement Therapies. 2002; 6(2):81-8. [DOI:10.1054/jbmt.2002.0271]

[12] Kannan P. Management of myofascial pain of upper trapezius: A three group comparison study. Global Journal of Health Science. 2012; 4(5):46-52. [DOI:10.5539/gihs.v4n5p46] [PMID] [PMCID] 
[13] Collins SL, Moore RA, McQuay HJ. The visual analogue pain intensity scale: What is moderate pain in millimetres? Pain. 1997; 72(1-2):95-7. [DOI:10.1016/S0304-3959(97)00005-5]

[14] Sciotti VM, Mittak VL, DiMarco L, Ford LM, Plezbert J, Santipadri E, et al. Clinical precision of myofascial trigger point location in the trapezius muscle. Pain. 2001; 93(3):25966. [DOI:10.1016/S0304-3959(01)00325-6]

[15] Hjermstad MJ, Fayers PM, Haugen DF, Caraceni A, Hanks GW, Loge JH, et al. Studies comparing Numerical Rating Scales, Verbal Rating Scales, and Visual Analogue Scales for assessment of pain intensity in adults: A systematic literature review. Journal of Pain and Symptom Management. 2011; 41(6):1073-93. [DOI:10.1016/j.jpainsymman.2010.08.016] [PMID]

[16] Simons D. Muscular pain syndromes. American Journal of Physical Medicine \& Rehabilitation.1975; 54(6):289-311

[17] Vučinić N, Erić M, Tomašević-Todorović S, Milekić B. Application of algometry in patients with cervical and lumbar radiculopathy. Journal of Back and Musculoskeletal Rehabilitation. 2018; 31(3):567-75. [DOI:10.3233/BMR-170965] [PMID]

[18] Reese NB, Bandy WD. Joint range of motion and muscle length testing-E-book. Amsterdam: Elsevier Health Sciences; 2016. https://books.google.com/ books?id $=$ oAzhCwAAQBAJ\&dq

[19] Fryer G, Hodgson L. The effect of manual pressure release on myofascial trigger points in the upper trapezius muscle. Journal of Bodywork and Movement Therapies. 2005; 9(4):248-55. [DOI:10.1016/j.jbmt.2005.02.002]

[20] Hakgüder A, Birtane M, Gürcan S, Kokino S, Nesrin Turan F. Efficacy of low level laser therapy in myofascial pain syndrome: An algometric and thermographic evaluation. Lasers in Surgery and Medicine: The Official Journal of the American Society for Laser Medicine and Surgery. 2003; 33(5):33943. [DOI:10.1002/lsm.10241] [PMID]

[21] Aguilera FJM, Martín DP, Masanet RA, Botella AC, Soler LB, Morell FB. Immediate effect of ultrasound and ischemic compression techniques for the treatment of trapezius latent myofascial trigger points in healthy subjects: A randomized controlled study. Journal of Manipulative and Physiological Therapeutics. 2009; 32(7):515-20. [DOI:10.1016/j. jmpt.2009.08.001] [PMID]

[22] Huang YY, Chen ACH, Carroll JD, Hamblin MR. Biphasic dose response in low level light therapy. Dose-Response 2009; 7(4):358-83. [DOI:10.2203/dose-response.09-027.Hamblin] [PMID] [PMCID]

[23] Thorsen H, Gam A, Svensson B, Jess M, Jensen M, Piculell I, et al. Low level laser therapy for myofascial pain in the neck and shoulder girdle. A double-blind, cross-over study. Scandinavian Journal of Rheumatology. 1992; 21(3):139-41. [DOI:10.3109/03009749209095086] [PMID]

[24] Falaki F, Nejat AH, Dalirsani Z. The effect of low-level laser therapy on trigeminal neuralgia: A review of literature. Journal of Dental Research, Dental Clinics, Dental Prospects. 2014; 8(1):1-5. [DOI:10.5681/joddd.2014.001] [PMID] [PMCID]

[25] Cagnie B, Dewitte V, Coppieters I, Van Oosterwijck J, Cools A, Danneels L. Effect of ischemic compression on trigger points in the neck and shoulder muscles in office workers: A cohort study. Journal of Manipulative and Physi- ological Therapeutics. 2013; 36(8):482-9. [DOI:10.1016/j. jmpt.2013.07.001] [PMID]

[26] de las Peñas CF, Campo MS, Carnero JF, Page JCM. Manual therapies in myofascial trigger point treatment: A systematic review. Journal of Bodywork and Movement Therapies. 2005; 9(1):27-34. [DOI:10.1016/j.jbmt.2003.11.001] 